\title{
la determinación de la resistencia a los sulfatos de los cementos, de acuerdo con los métodos rápidos convencionales
}

\author{
die beurteilung der sulfatheständigkeit von zementen nach \\ konventionellen schnellmethoden \\ W. LIEBER y K. BLEHER
}

( «Zement-Kalk-Gips», 13, núm. 7, julıo 1960, pág. 310.)

Se discuten todas las posibilidades y métodos propuestos para determinar la resistencia de los cementos a los sulfatos.

Como esta resistencia depende sobre todo del contenido del cemento en aluminato tricálcico, es muy indicado calcular su contenido según Bogue. Pero el cálculo no corresponde a la realidad. Por otro lado, este cálculo no puede aplicarse a los cementos que contienen escorias.

Los resultados de los ensayos con cementos sumergidos en soluciones de sulfatos no pueden aplicarse a probetas de mortero u hormigón. El método es, por tanto, inadecuado para determinar la resistencia de los cementos al ataque de los sulfatos.

El método de Anstett puede emplearse, al menos, para los cementos Portland. Es inadecuado en el caso de tratarse de otros cementos: cementos siderúrgicos y aluminosos. Se explican los causas por las que estos cementos son inadecuados para este ensayo. El método de Anstett debe ser considerado, pues, como inutilizable.

Ninguno de los métodos de ensayo rápido propuestos para la determinación de la resistencia a los sulfatos ha demostrado ser adaptado como método general. Se indica que, recientemente, se ha desarrollado un método adecuado por Koch y Steinegger. 